\title{
Anal sphincter damage after vaginal delivery: functional outcome and risk factors for fecal incontinence
}

\author{
Jan Willem de Leeuw ${ }^{1}$, Mark E. Vierhout ${ }^{1}$, Piet C. Struijk ${ }^{2}$, Wim C. J. Hop ${ }^{3}$ and Henk C. S. Wallenburg ${ }^{2}$ \\ From the Departments of Obstetrics and Gynecology, ${ }^{1}$ Ikazia Hospital, Rotterdam, ${ }^{2}$ Erasmus University Hospital, Rotterdam, \\ and the ${ }^{3}$ Department of Epidemiology and Biostatistics, Erasmus University, Rotterdam, The Netherlands
}

Acta Obstet Gynecol Scand 2001; 80: 830-834. (C) Acta Obstet Gynecol Scand 2001

Objective. To assess the role of anal sphincter damage following delivery in the development of anorectal complaints and urinary incontinence, and to identify obstetric factors associated with subsequent fecal incontinence.

Methods. The retrospective cohort study with matched controls used a postal questionnaire and analysis of delivery and operation records from all women who underwent primary repair of a third or fourth degree perineal rupture in our hospital between 1971 and 1991, and their controls, matched for date and parity. Frequencies of complaints were compared using the Mantel-Haenszel common odds ratio [OR] for matched-control studies. Obstetric risk factors for fecal incontinence were assessed with multivariate logistic regression analysis.

Results. In the period studied, 171 women underwent a primary repair. One hundred and forty-seven of which returned the questionnaire $(86 \%)$, compared with 131 of the controls (73\%). Analysis was performed on 125 matched pairs with a median follow-up of 14 years. Fecal incontinence was reported by 39 patients and 16 controls (OR: 3.09; 95\% confidence interval: 1.57-6.10). Urinary incontinence was reported by 65 cases and 52 controls (OR:1.46; 95\% CI: 0.91-2.37). Among women with anal sphincter damage, the extent of anal sphincter damage was an independent risk factor for fecal incontinence. (OR: 2.54; 95\% CI: 1.45-4.45). Subsequent vaginal delivery was not associated with the development of fecal incontinence (OR: 2.32; 95\% CI: 0.85-6.33). In primiparous women mediolateral episiotomy protected for fecal incontinence after anal sphincter damage (OR: 0.17; 95\% CI: 0.05-0.60).

Conclusions. Anal sphincter damage following delivery is significantly associated with subsequent anorectal complaints, but not with urinary incontinence. The extent of sphincter damage is an independent risk factor for the development of fecal incontinence. Mediolateral episiotomy protects for fecal incontinence in primiparous women.

Key words: anal sphincter; anorectal complaints; fecal incontinence; urinary incontinence

Submitted 27 January, 2001

Accepted 9 April, 2001

\section{Background}

Rupture of the anal sphincters during vaginal delivery is a known but relatively rare complication of vaginal delivery. Sequelae as perineal pain, sexual dysfunction, and fecal incontinence, urgency or soiling may develop.

Abbreviation:

OR: : odds ratio.
The incidence of third and fourth degree perineal ruptures appears to vary in reports from different countries. European studies report incidences between 0.5 and $3 \%$, whereas studies from the United States show rates up to $25 \%(1,2)$. Studies on the functional outcome of primary repair of third and fourth degree ruptures have shown that fecal incontinence may develop in up to $57 \%$ of women. Most of these studies, however, contain small numbers of patients (3-7), lack con- 
trol groups (7-10) or a sufficient follow-up period $(3-5,9)$ which hampers a reliable interpretation of these results.

We present the results of a large retrospective cohort study, with a median follow-up of 14 years. The aim of our study was to assess the functional outcome after primary repair of third and fourth degree perineal ruptures in comparison with the outcome in controls with a vaginal delivery without anal sphincter damage, and to analyze obstetric risk factors for the development of anorectal complaints after anal sphincter damage complicating vaginal delivery.

\section{Methods}

The study was designed as a retrospective cohort study with matched controls and was approved by the Medical Ethics Committee of the Ikazia Hospital, Rotterdam. All 171 women who underwent primary repair of a third and fourth degree perineal rupture between January 1st 1971 and December 31st 1990 in the Ikazia Hospital were included in the study. This group comprised women who were delivered in the hospital attended by the obstetrician-gynecologist, as well as women referred $(73 \%)$ after home delivery under supervision of an independent midwife or general practitioner. The first woman after the index case, matched for parity, who had a vaginal delivery without anal sphincter damage in our hospital was selected as a control. All relevant data were obtained from the hospital records. Anal sphincter damage was classified in three groups: Partial rupture of the anal sphincters (grade-IIIa), complete rupture of the sphincters with intact anal mucosa (gradeIIIb), and complete rupture of the anal sphincters and mucosa (grade-IV).

In the 20-year period covered by the study, the surgical technique of primary repair remained unchanged. Sphincter muscle ends were approximated end-to-end using interrupted chromic catgut sutures. The anal mucosa was closed separately with interrupted chromic catgut sutures if necessary. A nylon suture through the perineal skin and both sphincter ends was used and left in place for one week, to secure approximation of both sphincter ends. Vaginal mucosa, perineal muscles and skin were repaired as in routine second-degree rupture or episiotomy. All women received prophylactic antibiotic treatment and were treated during the first postoperative week with bedrest, laudanum to reduce bowel movements and lactulose to soften stools.

A questionnaire was sent to all patients and matched controls with questions about the obstetric and medical history, general health, daily defec- atory pattern, and complaints of fecal soiling, fecal and urinary incontinence or urgency. If the questionnaire was not returned after three weeks a reminder was sent. Complaints of incontinence were scored positive if they were reported to occur more than once a week during a period of at least one year. The severity of complaints of fecal incontinence was classified according to Parks' classification (11). The frequency of complaints was classified as less than once a week, one to six times per week, one to five times a day or more than five times a day.

Statistical testing of comparisons between index cases and controls regarding general and obstetric characteristics was performed using McNemar's test or Wilcoxon's signed-rank test for qualitative or continuous data. Comparisons of the functional outcomes between both groups were evaluated with the Mantel-Haenzsel common odds ratio estimate for matched case-control studies. Univariate analysis of risk factors for the development of anorectal complaints after anal sphincter damage was performed with calculations of odds-ratios with 95\%-confidence intervals. Multiple logistic regression analyses were performed to assess independent risk factors. A two-sided $p$-value of 0.05 was considered to be the limit of statistical significance. Analyses were done with the Statistical Package for Social Sciences, version 7.0 for Windows (SPSS Inc., Chicago, IL).

\section{Results}

Of 171 women with anal sphincter damage, 147 $(86 \%)$ returned a completed questionnaire; ten women refused participation in the study, and 14 were lost to follow-up. Of 171 controls, 131 (73\%) returned a completed questionnaire; 27 refused participation and 13 women were lost to followup. Of 147 index cases and 131 controls, 125 matched pairs remained and formed the subject of this study.

In the case group, 67 women (54\%) had a gradeIIIa rupture, 36 women $(29 \%)$ a grade-IIIb rupture, and 22 women $(18 \%)$ a grade-IV rupture. Table I lists the general characteristics of both groups. All episiotomies were of the mediolateral type. There were no significant differences between the groups except a higher birthweight in the case group and more mediolateral episiotomies in the control group. The median follow-up in both groups was 14 years. Separate analysis comparing responders and nonresponders within both study groups showed no differences.

All forms of fecal incontinence were significantly more common in the group with sphincter damage (Table II). A total of $40 \%$ of women in the case 
Table I. General characteristics*

\begin{tabular}{lcc}
\hline & Cases $(n=125)$ & Controls $(n=125)$ \\
\hline Age at delivery (yrs) & $26(18-41)$ & $28(19-38)$ \\
Age at questionnaire (yrs) & $40(27-59)$ & $41(24-58)$ \\
Duration of follow-up (yrs) & $14(5-24)$ & $14(5-24)$ \\
Gestational age (wks) & $39(36-42)$ & $38(35-41)$ \\
Parity & $1(1-3)$ & $1(1-4)$ \\
Number of subsequent deliveries & $1(0-4)$ & $1(0-6)$ \\
Birthweight (gm) & $3620(2060-5700)$ & $3430(1870-4380)^{\dagger}$ \\
Vacuum extraction & $7[5.6]$ & $13[10.4]$ \\
Forceps delivery & $2[1.6]$ & 0 \\
Occipitoposterior presentation & $5[4.0]$ & $1[0.8]$ \\
Breech delivery & $4[3.2]$ & $6[4.8]$ \\
Mediolateral episiotomy & $47[37.6]$ & $70[56.0]^{\dagger}$ \\
\hline
\end{tabular}

${ }^{*}$ Values are presented as median (range) or total number [\%]. ${ }^{\dagger} p<0.05$

Table II. Prevalence of complaints*

\begin{tabular}{lccc}
\hline & $\begin{array}{c}\text { Cases } \\
(n=125)\end{array}$ & $\begin{array}{c}\text { Controls } \\
(n=125)\end{array}$ & $\begin{array}{c}\text { Mantel-Haenszel } \\
\text { Common Odds-ratio } \\
{[95 \%-C I]}\end{array}$ \\
\hline Anorectal complaints & $50(40)$ & $19(15)$ & $3.64[1.87-7.09]$ \\
Fecal incontinence & $39(31)$ & $16(13)$ & $3.09[1.57-6.10]$ \\
$\quad$ Grade-II & $28(22)$ & $14(11)$ & \\
Grade-III & $10(8)$ & $2(2)$ & \\
Grade-IV & $1(1)$ & 0 & \\
Fecal urgency & $32(26)$ & $7(6)$ & $7.25[2.55-20.62]$ \\
Fecal soiling & $12(10)$ & $1(1)$ & $12.00[1.56-92.29]$ \\
Urinary incontinence & $65(52)$ & $52(42)$ & $1.46[0.91-2.37]$ \\
$\quad$ Stress-incontinence & $63(50)$ & $50(40)$ & $1.46[0.91-2.37]$ \\
Urge-incontinence & $32(26)$ & $28(22)$ & $1.16[0.68-1.98]$ \\
\hline
\end{tabular}

* Values are presented as $n(\%)$

group reported some kind of anorectal problem, compared to $15 \%$ of women in the control group.

Separate analysis of women with anorectal complaints showed that in the group of women with sphincter damage these complaints of incontinence started significantly earlier compared to controls. In $69 \%$ of cases complaints started in the first three months after delivery, compared to $31 \%$ in controls $(p=0.003)$. Classified according to Parks' classification, complaints of fecal incontinence were more severe in cases compared to controls $(p<0.001)$. Also the rate of occurrence was significantly higher in the case group $(p=0.004)$.

In more than $90 \%$ of women with anorectal complaints these were still present at the time of the questionnaire. Only a minority underwent earlier treatment for their complaints; 14 were treated conservatively with dietary measures or physiotherapy, whereas two women underwent anterior sphincter repair.

In contrast to anorectal complaints, neither stress- nor urge-incontinence for urine were found to be associated with previous anal sphincter damage during delivery.
Characteristics such as maternal age at delivery and current age, number of subsequent vaginal deliveries, and obstetric factors such as parity, gestational age, mode of delivery, fetal birthweight and presentation, extent of sphincter damage and presence of an episiotomy were tested as potential risk factors for the development of fecal incontinence after anal sphincter damage. Using univariate analysis only, the extent of anal sphincter damage and the presence of a mediolateral episiotomy appeared to be associated with the development of fecal incontinence (Table III). Women with a grade-IIIa rupture reported complaints in $21 \%$, women with a grade-IIIb rupture in $31 \%$, and women with grade-IV-ruptures in $64 \%$ of cases.

Stepwise logistic regression analysis confirmed the extent of sphincter damage to be the primary independent risk factor for the development of fecal incontinence. Using the subdivision of gradeIIIa, IIIb and IV ruptures, the odds for the development of fecal incontinence increased more than twofold with each step (Table III).

While univariate analysis suggested that mediolateral episiotomy had a weak protective effect for the development of fecal incontinence, multivariate analysis showed that this effect was only present in primiparae. Of the primiparae without a mediolateral episiotomy and anal sphincter damage, 46\% developed fecal incontinence, compared to $12 \%$ of the primiparae with anal sphincter damage combined with a mediolateral episiotomy $(p=0.003)$. In multiparae these figures were, respectively, $32 \%$ and $44 \%(p=0.47)$. The odds for primiparae with episiotomy in the case group to develop fecal incontinence, adjusted for the extent of sphincter damage, was reduced by $83 \%(p=0.005)$, compared to other women.

Women who had one or more vaginal deliveries following the delivery with anal sphincter damage reported complaints in $41 \%$, compared to $39 \%$ of those who did not deliver vaginally after the delivery in which the sphincter damage occurred. Multivariate analysis showed that fecal incontinence was not significantly positively associated with subsequent vaginal deliveries. In none of the analyses was an association found between fecal incontinence and the age at the moment of delivery or the duration of follow-up, the latter being minimally 5 years.

The group of 16 women with fecal incontinence in the control group was too small to analyze for risk factors.

\section{Discussion}

During the last decade the relationship between vaginal delivery and subsequent urinary and fecal 
Table III. Univariate and multivariate analysis of various risk factors for fecal incontinence after anal sphincter damage during delivery*

\begin{tabular}{|c|c|c|}
\hline & Univariate analysis & Multivariate analysis \\
\hline Extent of perineal damage ${ }^{\dagger}$ & $2.44[1.46-4.06]<0.001$ & $2.54[1.45-4.45] 0.001$ \\
\hline Subsequent vaginal delivery & $1.09[0.50-2.34] \quad 0.83$ & $2.32[0.85-6.33] 0.10$ \\
\hline Primiparity ${ }^{\ddagger}$ & $0.79[0.37-1.69]$ & $\begin{array}{l}1.16^{\mathrm{a}}[0.41-3.29] 0.78 \\
0.15^{\mathrm{b}}[0.02-0.98] 0.05\end{array}$ \\
\hline Mediolateral episiotomy ${ }^{\ddagger}$ & $0.38[0.15-0.91]$ & $\begin{array}{l}0.17^{\mathrm{c}}[0.05-0.61] 0.007 \\
1.25^{\mathrm{d}}[0.27-5.83] 0.78\end{array}$ \\
\hline
\end{tabular}

${ }^{*}$ values are presented as odds ratios with [95\%-confidence interval] and $p$-values.

† per grade: grade-IV vs. grade-IIIb vs. grade-IIIa.

‡ significant difference: awithout episiotomy vs. ${ }^{b}$ with episiotomy, and cprimiparity vs. ${ }^{\mathrm{d}}$ multiparity.

incontinence has received increasing interest (1217), in particular with regard to the contribution of anal sphincter damage $(3-10,18,19)$. These studies indicate a significant but variable association between anal sphincter damage following vaginal delivery and subsequent anorectal complaints. The variability in results may be attributed, at least in part, to small study size and short follow-up, or both. Our questionnaire-based study contained large numbers in case and control groups, with high response rates, which makes selection bias unlikely. The extensive period of follow-up allows assessment of long-term consequences of anal sphincter damage during delivery.

The study and control groups were similar regarding their general characteristics, except for a lower median fetal birthweight and a higher incidence of episiotomy in controls (Table I). These differences can be explained by the recruitment of the control group entirely from women who delivered in the hospital under specialist care, with more pregnancies and deliveries at risk than in the case group, $73 \%$ of which were delivered at home.

Anal sphincter damage was found to be significantly associated with fecal incontinence, which is in accordance with the results of earlier studies (3$10,18,19)$. The occurrence of fecal urgency in women with anal sphincter damage in our study is similar to that reported by Sultan et al. (4). Our findings with regard to fecal soiling confirm the results of earlier studies in which fecal soiling is reported in 7 to 10 percent of women with anal sphincter damage after delivery $(10,19)$.

The results of the two previously published studies with a follow-up of more than ten years, with regard to the occurrence of anorectal complaints, are contradictory $(6,19)$. Nygaard et al. (6) reported no significant difference in the rate of frequent flatus incontinence in women with anal sphincter damage compared to women with episiotomy only, and frequent fecal incontinence was significantly even more common in the latter group. This may be explained by the high rates for frequent flatus and fecal incontinence in the control group of $30.3 \%$ and $18.0 \%$, respectively. A recent study from the United States showed similar high incontinence rates in women after midline episiotomy without visible extension (20). These rates are much higher than those reported in our control group and in control groups of other European studies $(4,5,18,19)$. The differences may be explained by a high incidence of unrecognized sphincter damage after midline episiotomy. This procedure is known to increase the risk of anal sphincter damage which may be difficult to recognize $(2,17)$. Our study confirms the results of the study of Haadem and Gudmundsson (19) in which anorectal complaints were significantly more often present in women with anal sphincter damage almost two decades after delivery compared to women without anal sphincter damage.

Our study shows that in women with a third and fourth degree perineal tear complaints start significantly earlier after delivery and are more severe than in controls, an issue not addressed in any of the earlier studies. The fact that only a minority of women underwent treatment for their complaints is in line with previous reports and indicates that many women may be reluctant to discuss the problem with their physician, or that their complaints are not taken seriously $(6,19)$.

Findings with regard to urinary incontinence in our study confirm the results of Nygaard et al. (6) and Haadem and Gudmundsson (19) and support evidence that the development of urinary incontinence after delivery may mainly be due to general damage or denervation of the pelvic floor, which is not significantly affected by rupture of the anal sphincter complex (16).

Knowledge of risk factors for the development of fecal incontinence after anal sphincter damage is needed for adequate counseling of women with previous sphincter damage. Using stepwise logistic 
regression analysis we identified the extent of anal sphincter damage as an independent risk factor for the development of fecal incontinence. Tetzschner et al. (18), using a different classification of anal sphincter damage, found no association between the extent of damage and subsequent fecal incontinence. Their classification with a very discrete classification of sphincter damage may be difficult to use in daily practice. Our findings confirm the results of Poen et al. (10) and Haadem et al. (21), who also found an increased risk for development of fecal incontinence after involvement of the anal mucosa.

In contrast to the findings reported by Møller Bek and Laurberg (8), who reported an increased risk of fecal incontinence after subsequent vaginal delivery in women with mild or transient symptoms, and Sangalli et al. (22), who reported an increased risk of fecal incontinence in women with fourth degree tears, our findings showed that subsequent vaginal deliveries were not associated with an increased risk of fecal incontinence after anal sphincter damage during delivery. The observed protective effect of mediolateral episiotomy for the development of fecal incontinence in primiparous women is of note. Only mediolateral episiotomies were performed, as is common practice in The Netherlands. The protective effect may be explained by reduced stretching of the perineum in women with episiotomy, as prolonged stretching of the pelvic floor and the pudendal nerve may aggravate complaints of fecal incontinence $(18,23)$. Further study is necessary to elucidate the role of mediolateral episiotomy in the development of fecal incontinence after anal sphincter damage during delivery.

\section{References}

1. Thacker SB, Banta DH. Benefits and risks of episiotomy: an interpretative review of the English language literature, 1860-1980. Obstet Gynecol Surv 1983; 38: 322-38.

2. Woolley RJ. Benefits and risks of episiotomy: an interpretative review of the English-language literature since 1980. Obstet Gynecol Surv 1995; 50: 806-35.

3. Crawford LA, Quint EH, Pearl ML, DeLancey JOL. Incontinence following rupture of the anal sphincter during delivery. Obstet Gynecol 1993; 82: 527-31.

4. Sultan AH, Kamm MA, Hudson CN, Bartram CI. Third degree obstetric anal sphincter tears: risk factors and outcome of primary repair. BMJ 1994; 308: 887-91.

5. Uustal Fornell EK, Berg G, Halböök O, Matthiesen LS, Sjödahl R. Clinical consequences of anal sphincter rupture during vaginal delivery. J Am Coll Surg 1996; 183: 553-8.

6. Nygaard IE, Rao SSC, Dawson JD. Anal incontinence after anal sphincter disruption: a 30-year retrospective cohort study. Obstet Gynecol 1997; 89: 896-901.
7. Gjessing H, Backe B, Sahlin Y. Third degree obstetric tears; outcome after primary repair. Acta Obstet Gynecol Scand 1998; 77: 736-40.

8. Møller Bek K, Laurberg S. Risk of anal incontinence from subsequent vaginal delivery after a complete obstetric anal sphincter tear. Br J Obstet Gynaecol 1992; 99: 724-6.

9. Walsh CJ, Mooney EF, Upton GJ, Motson RW. Incidence of third degree perineal tears in labour and outcome after primary repair. Br J Surg 1996; 83: 218-21.

10. Poen AC, Felt-Bersma RJF, Strijers RLM, Dekker GA, Cuesta MA, Meuwissen SGM. Third-degree obstetric perineal tear: long-term clinical and functional results after primary repair. Br J Surg 1998; 85: 1433-8.

11. Parks AG. Anorectal incontinence. Proc R Soc Med 1975; 68: 681-90.

12. Kamm MA. Obstetric damage and faecal incontinence. Lancet 1994; 344: 730-3.

13. Ryhammer AM, Møller Bek K, Laurberg S. Multiple vaginal deliveries increase the risk of permanent incontinence of flatus and urine in normal premenopausal women. Dis Colon Rectum 1995; 208: 1206-9.

14. MacArthur C, Bick DE, Keighley MRB. Faecal incontinence after childbirth. Br J Obstet Gynaecol 1997; 104: 4650 .

15. Connolly AM, Thorp JM. Childbirth-related perineal trauma: Clinical significance and prevention. Clin Obstet Gynecol 1999; 42: 820-35.

16. Chaliha C, Sultan AH, Stanton SL. Changes in the pelvic floor following childbirth. Fetal Matern Med Rev 1999; 11: $41-54$.

17. Sultan AH, Kamm MA, Hudson CN, Thomas JM, Bartram CI. Anal sphincter disruption during vaginal delivery. N Engl J Med 1993; 329: 1905-11.

18. Tetzschner T, Sørensen M, Lose G, Christiansen J. Anal and urinary incontinence in women with obstetric anal sphincter rupture. Br J Obstet Gynaecol 1996; 103: 1034 40.

19. Haadem K, Gudmundsson S. Can women with intrapartum rupture of anal sphincter still suffer after-effects two decades later? Acta Obstet Gynecol Scand 1997; 76: 601-3.

20. Signorello LB, Harlow BL, Chekos AK, Repke JT. Midline episiotomy and anal incontinence: retrospective cohort study. BMJ 2000; 320: 86-90.

21. Haadem K, Ohrlander S, Lingman G. Long-term ailments due to anal sphincter rupture caused by delivery - a hidden problem. Eur J Obstet Gynecol Reprod Biol 1988; 27: 2732.

22. Sangalli MR, Floris L, Faltin D, Weil A. Anal incontinence in women with third and fourth degree perineal tears and subsequent deliveries. Aust N Z J Obstet Gynaecol 2000; 40: 244-8.

23. Allen RE, Hosker GL, Smith ARB, Warrel DW. Pelvic floor damage and childbirth: a neurophysiologic study. Br J Obstet Gynaecol 1990; 97: 770-9.

Address for correspondence:

J. W. de Leeuw, M.D.

Ikazia Hospital

Montessoriweg 1

3083 AN Rotterdam

The Netherlands

e-mail: ikagyn@hotmail.com 